
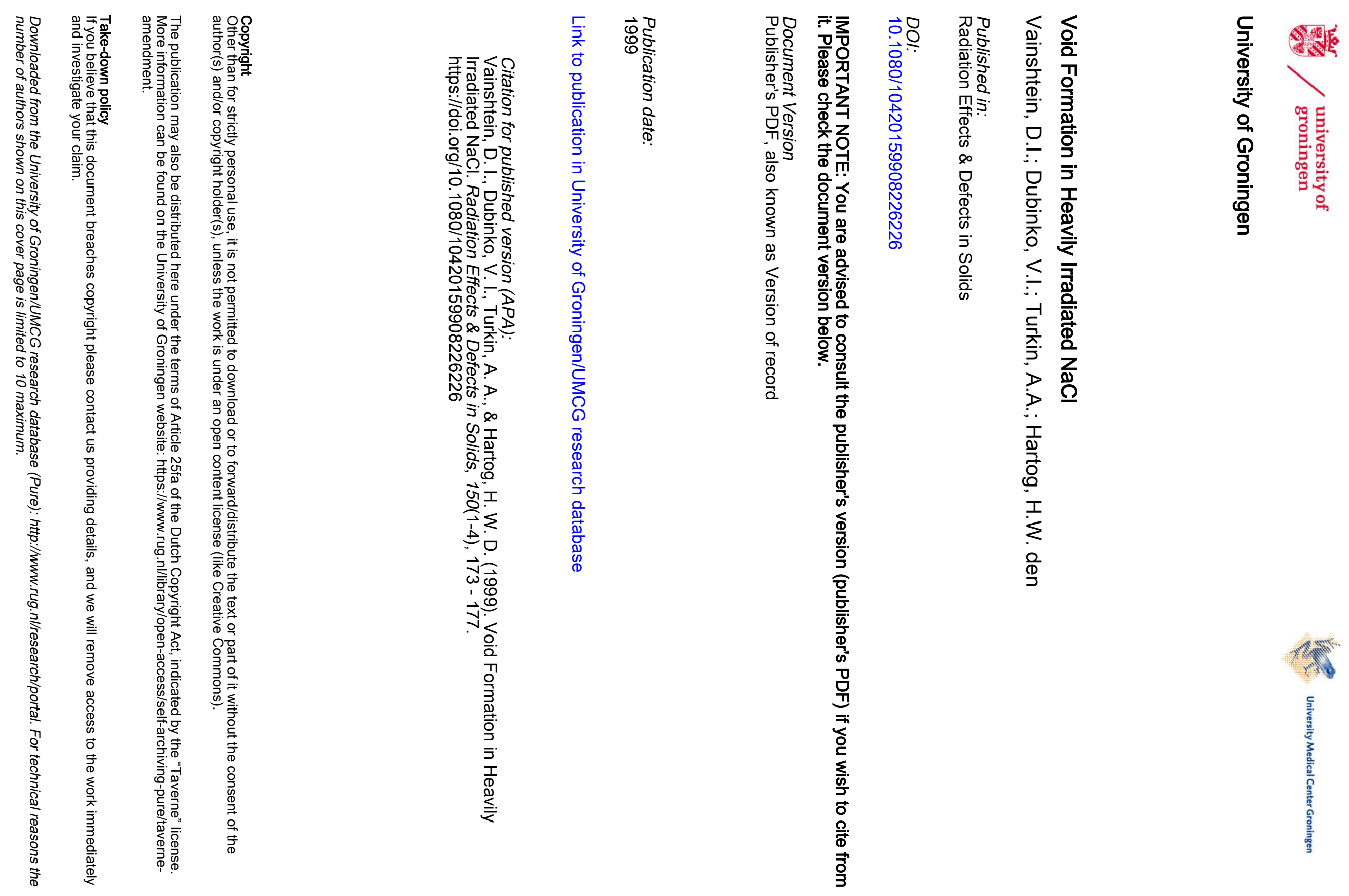


\title{
VOID FORMATION IN HEAVILY IRRADIATED NaCl
}

\author{
D.I. VAINSHTEIN ${ }^{a} *$, V.I. DUBINKO ${ }^{b}$, A.A. TURKIN ${ }^{b}$ \\ and H.W. DEN HARTOG ${ }^{\mathrm{a}}$ \\ ${ }^{a}$ Solid State Physics Laboratory, University of Groningen, 4 Nijenborgh, \\ NL-9747 AG Groningen. The Netherlands; ${ }^{b}$ Kharkov Institute of Physics \\ and Technology, 310108 Kharkov, Ukraine
}

(Received 6 July 1998; In final form 20 September 1998)

\begin{abstract}
Experimental and theoretical results are presented on the formation of voids discovered recently in heavily irradiated $\mathrm{NaCl}$. Experimental data show that for $\mathrm{NaCl}$ samples with particular dopants, the development of radiation damage, such as $\mathrm{Na}$-colloids, chlorine inclusions and voids does not show a saturation as a function of the dose. A quantitative comparison of the new model (Dubinko et al., These proceedings) for radiation damage in alkali halides with experimental data is presented. Mean sizes and volume fractions of all types of observed defects are calculated. It is shown that voids formed due to agglomeration of $\mathrm{F}$ centers and cation vacancies can grow to the dimensions exceeding the mean distance between colloids and bubbles, eventually absorbing them, and, hence, bringing the halogen gas and metal to a back reaction. Impurities are shown to play a major role in the void development with increasing irradiation dose, which strongly affects the radiation stability of $\mathrm{NaCl}$.
\end{abstract}

Keywords: Radiation damage; $\mathrm{NaCl}$; Vacancy voids

\section{INTRODUCTION}

The natural and doped $\mathrm{NaCl}$ crystals have been irradiated with $1.35 \mathrm{MeV}$ electrons up to fluences $6 \times 10^{18}$ electrons $/ \mathrm{cm}^{2}$ that corresponded to doses of $150 \mathrm{Grad}$ (about 30 displacements per atom) at

\footnotetext{
* Corresponding author.
} 
temperatures between $50^{\circ} \mathrm{C}$ and $150^{\circ} \mathrm{C}$. Scanning electron microscopy (SEM) in combination with differential scanning calorimetry (DSC) and Electron Spin Resonance (ESR) were used to study the void production. The concentration of the metallic $\mathrm{Na}$ was deduced from measurements of the latent heat of melting of metallic $\mathrm{Na}$ in combination with ESR.

Formation of large voids (above $100 \mathrm{~nm}$ in diameter) correlates with an eventual destruction of the samples under heavy irradiation or heating without any observable loss of the specimen weight, which confirms that the cavities are vacancy voids rather than gas-filled bubbles. As can be seen from Fig. 1, impurities strongly affect the void development as well as the accumulation of metallic $\mathrm{Na}$.

A quantitative comparison of a new model of radiation damage in alkali halides, described in the companion paper [1] with experimental data, is presented below.
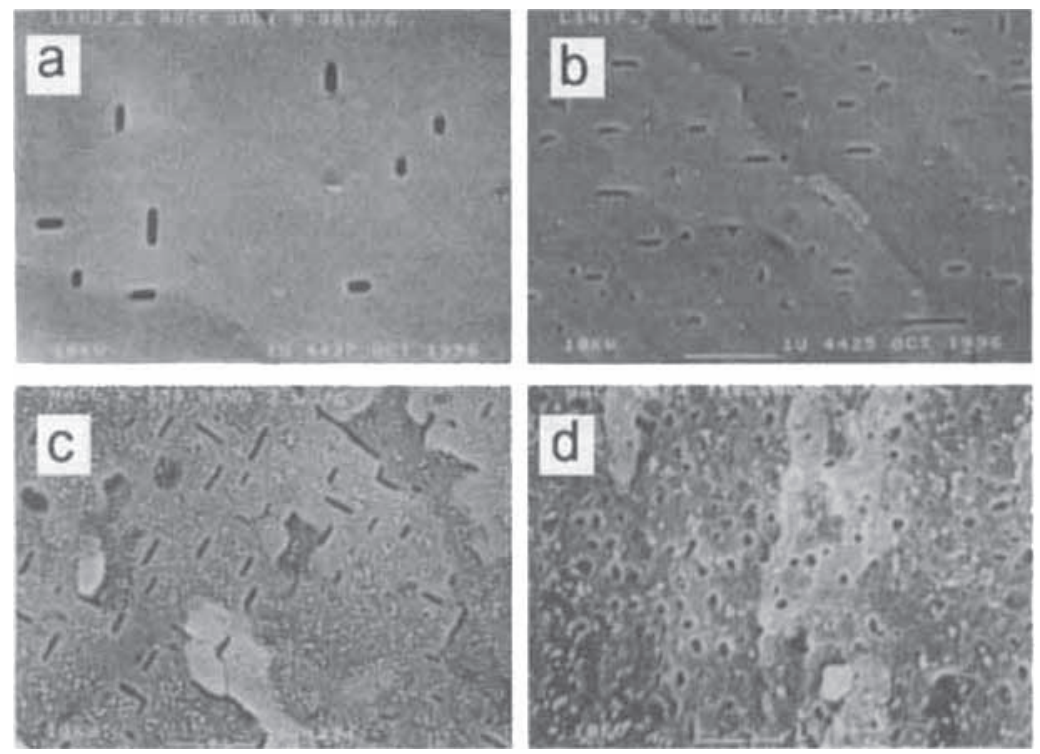

FIGURE 1 SEM micrographs showing vacancy voids in $\mathrm{NaCl}$ samples irradiated with electrons to a dose of $150 \mathrm{Grad}$. (a) and (b) natural rock salt samples irradiated at $140^{\circ} \mathrm{C}$ and $70^{\circ} \mathrm{C}$, LHM of metallic $\mathrm{Na}$ is $0.8 \mathrm{~J} / \mathrm{g}$ and $2.5 \mathrm{~J} / \mathrm{g}$, respectively; (c) $\mathrm{NaCl}+\mathrm{K}(0.1 \mathrm{~mol} \%)$ irradiated at $100^{\circ} \mathrm{C}$, LHM of metallic $\mathrm{Na}$ is $3.6 \mathrm{~J} / \mathrm{g}$; (d) $\mathrm{NaCl}+\mathrm{KBF}_{4}(0.03 \mathrm{~mol} \%)$ irradiated at $100 \mathrm{C}$, LHM of metallic $\mathrm{Na}$ is $5.6 \mathrm{~J} / \mathrm{g}$. 


\section{COMPARISON OF THE MODEL PREDICTIONS WITH EXPERIMENTAL DATA}

Figure 2 illustrates the radiation-induced reactions between point defects (PD) and extended defects (ED) based on the present model [1]. Primary radiation $\mathrm{PD}$, namely, $\mathrm{H}$ and $\mathrm{F}$ centers, separate ultimately into bubbles, dislocations and metal colloids, which results in production of the secondary PD (cation vacancies) and ED (interstitial loops and vacancy voids). Based on the model, a complete set of the rate equations for PD and growth rates for ED was derived, which is described in detail elsewhere [2]. An asymptotic (in time of irradiation) solution to these equations was obtained [2] in the temperature range above $0.3 T_{\mathrm{m}}$ ( $T_{\mathrm{m}}$ is the melting point), in which both anion and cation PD are mobile, but below the temperature $T^{\text {th }}$, at which thermal

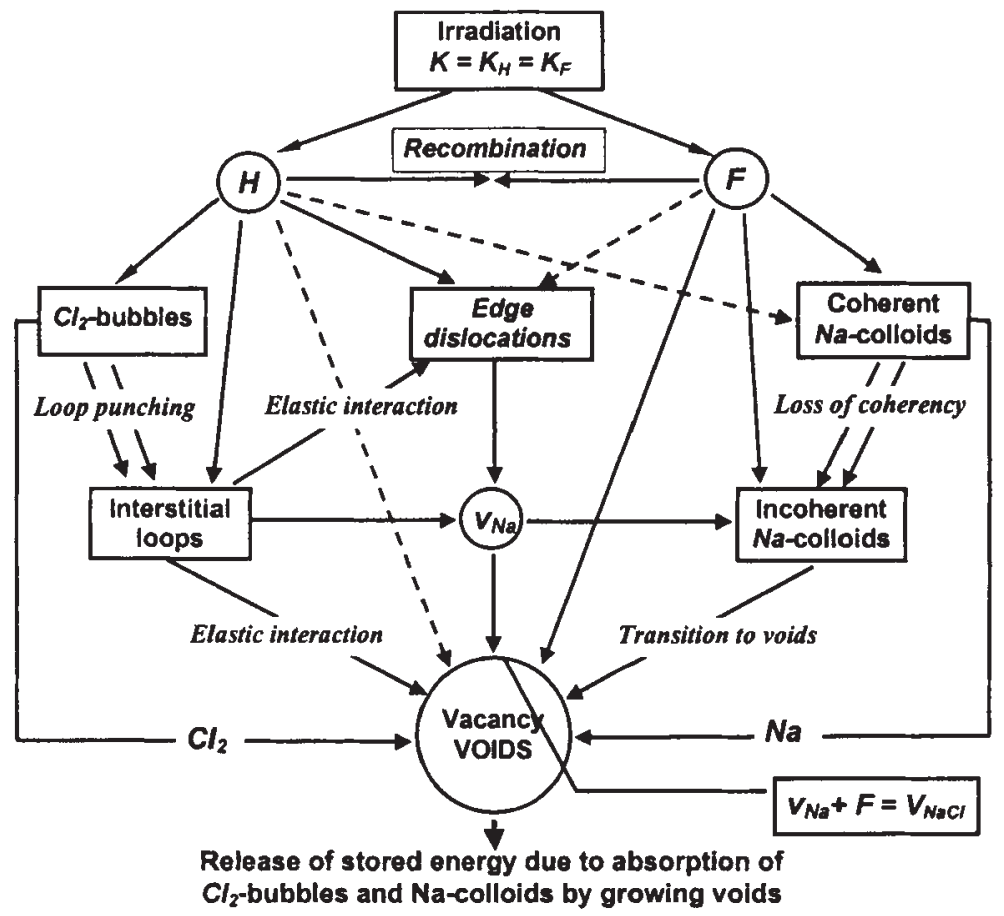

FIGURE 2 Diagram of radiation-induced reactions betwcen point defects (H- and F-centers, and cation vacancies) and extended defects (bubbles, dislocations and colloids) resulting in the void formation. 
TABLE I Principal material and irradiation parameters used for the calculations in the present paper

\begin{tabular}{|c|c|c|c|}
\hline Parameter & Value & Parameter & Value \\
\hline Dislocation bias, $\delta_{\mathrm{d}}$ & 0.5 & Irradiation temperature, $T,{ }^{\circ} \mathrm{C}$ & 100 \\
\hline$\delta_{\mathrm{eff}}=\delta_{\mathrm{d}}-\alpha_{\mu}\left(\sigma_{\varepsilon} / \mu\right)^{2}$ & 0.1 & Dose rate, $K, \mathrm{Mrad} / \mathrm{h}(\mathrm{dpa} / \mathrm{s})$ & $120\left(6 \times 10^{-6}\right)$ \\
\hline $\begin{array}{l}\text { "Image" interaction } \\
\text { constant, } \alpha_{i m}\end{array}$ & 0.1 & RIC upper temperature, $T^{\text {th }}(\mathrm{K}),{ }^{\circ} \mathrm{C}$ & 220 \\
\hline $\begin{array}{l}\text { Modulus interaction } \\
\text { constant, } \alpha_{\mu}\end{array}$ & 100 & Maximum dose, Grad (dpa) & $150(30)$ \\
\hline Shear modulus, $\mu, \mathrm{GPa}$ & 15 & $\mathrm{~F}-\mathrm{H}$ recombination constant, $\mathrm{m}^{-2}$ & $10^{20}$ \\
\hline $\begin{array}{l}\text { Colloid shear } \\
\text { modulus, } \mu_{\mathrm{C}}, \mathrm{GPa}\end{array}$ & 3.3 & Dislocation density, $\rho, \mathrm{m}^{-2}$ & $1 \times 10^{14}-5 \times 10^{14}$ \\
\hline Colloid misfit, $\varepsilon$ & 0.05 & Void nucleation rate, $J_{\mathrm{v}}, \mathrm{dpa}^{-1} \mathrm{~m}^{-3}$ & $10^{18}-10^{19}$ \\
\hline
\end{tabular}

evaporation of PD from ED starts to play essential role and suppress the growth of ED. In this region, the growth or shrinkage rates of different kinds of ED and their sizes are determined by the difference between the incoming fluxes of radiation produced $\mathrm{PD}$, which is determined by several material constants presented in Table I. We have used experimentally observed values for the mean dislocation density, $\rho$, and the void nucleation rate, $J_{\mathrm{v}}$, as the only input microstructural parameters (see Table I). The mean sizes and number densities of colloids and bubbles as well as the mean size of voids have been calculated as a function of irradiation dose at the stage when the nucleation stage of colloids is over. Under this condition, the colloid number density is independent of the initial conditions and is determined by the radiationinduced coarsening (RIC) mechanism, as was originally proposed for voids in irradiated metals [3].

Figure 3(a) shows the measured dose dependence of the latent heat of melting (LHM) of $\mathrm{Na}$ (which is proportional to the total content of metallic $\mathrm{Na}$ ) in samples doped with different impurities along with the theoretical curves corresponding to different dislocation densities. Figure 3(b)-(d) shows the measured and calculated dependencies of void parameters on LHM. The mean sizes and number densities of colloids and bubbles werc not measured, while their maximum theoretical values were found to be about $6 \mathrm{~nm}$ and $10^{23} \mathrm{~m}^{-3}$, respectively, as compared to $60 \mathrm{~nm}$ and $5 \times 10^{19} \mathrm{~m}^{-3}$ for voids. ${ }^{\dagger}$ For doses higher than

\footnotetext{
${ }^{\dagger}$ Note that in the Fig. 3(c), the void number density was measured at the sample surface, and the value $5 \times 10^{19} \mathrm{~m}^{-3}$ is the corresponding void number per unit volume.
} 


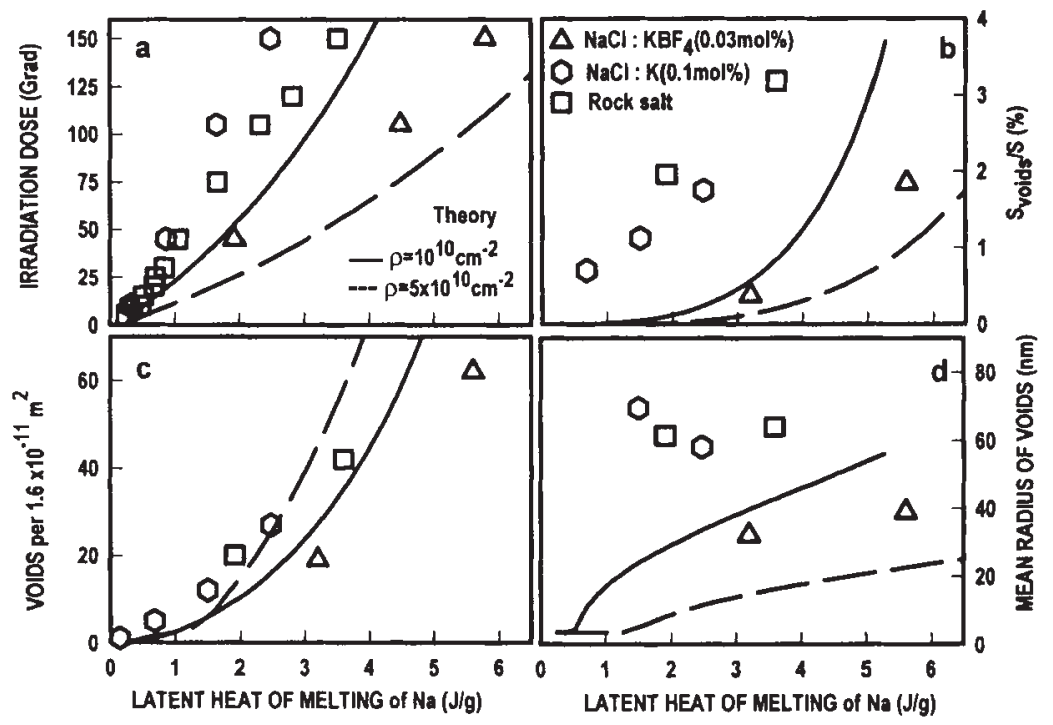

FIGURE 3 Measured and calculated dependence of LHM of metallic Na on irradiation dose (a), and the void mean parameters against LHM for different dopants and dislocation densities, $\rho$. Symbols - experimental data, curves - theory.

$50 \mathrm{Grad}$, the void dimensions exceed the mean distance between colloids and bubbles, which makes possible the capture of the latter by growing voids that would eventually bring the halogen gas and metal to a back reaction, as discussed in the previous paper [1].

\section{Acknowledgment}

This study is supported by the Dutch Ministry for Economic Affairs.

\section{References}

[1] V.I. Dubinko, A.A. Turkin, D.I. Vainshtein and H.W. den Hartog, New formulation of the modeling of radiation-induced microstructure evolution in alkali halides, These proceedings,

[2] V.I. Dubinko, A.A. Turkin, D.I. Vainshtein and H.W. den Hartog (to be published).

[3] V.I. Dubinko, P.N. Ostapchuk and V.V. Slezov. J. Nucl. Maler. 161, 239 (1989). 